\title{
Feminist Activism against Rape Culture
}

\author{
Claudia Mitchell
}

\section{$\cos 80$}

I met Roxanne Harde, the guest editor of this Special Issue, at the Second International Girls Studies Association conference in 2019 when I attended the panel discussion, "Representations of Rape in Young Adult Fiction." I recall Roxanne's passion vividly and, indeed, the enthusiasm of all three presenters as they discussed a variety of texts in superb presentations that aligned well with Ann Smith's notion of feminism in action in their seeing "a fictional text not only as a literary investigation into issues of concern to its author but also as the site of educational research" (2000: 245). Their papers pointed to the ways in which the analysis of how rape culture is treated in Young Adult (YA) literature, film, and the print media can take scholars and activists so much further into the issues, and, at the same time, noted the ways in which rape culture in all its manifestations as a global phenomenon has inevitably led to its becoming an everyday topic of YA fiction.

As someone who works closely with preservice English teachers, I asked if any of the speakers had worked with adolescent girl readers of this fiction. I was, of course, thinking of what a rich resource this panel could offer to educators in general and, at that moment, the idea of a Special Issue on Rape Culture in relation to girls was born. It was decided during the incubation process of drawing up the call that Roxanne would extend it to invite "particular emphasis on literary and visual representations." As a result, this Special Issue draws together the analysis of rape culture in YA literature, film, periodicals (including tabloid newspapers), and archived records as part of feminist educational research in relation to social change and the activist agenda that involves working with adolescent girls on how they "react to and against, are represented as part of, and are affected by rape culture." Both agendas, as the articles in this Special Issue highlight, are vital. 


\section{Reference}

Smith, Ann. 2000. "Girl-power in Nervous Conditions: Fictional Practice as a

Research Site.” McGill Journal of Education 35 (3): 245-260. 